\title{
Superplastic deformation behavior of ultra-fine-grained Ti-1V- 4Al-3Mo alloy: constitutive modeling and processing map
}

\author{
A.O Mosleh ${ }^{1,2}$, A. V Mikhaylovskaya ${ }^{1}$, A. D Kotov ${ }^{1}$, M Sitkina $^{1}$, P Mestre-Rinn ${ }^{3}$ and J. S Kwame ${ }^{4}$ \\ ${ }^{1}$ National University of Science and Technology 'MISiS', Leninsky Prospekt, 4, Moscow 119049, \\ Russia \\ ${ }^{2}$ Shoubra Faculty of Engineering, Benha University, Shoubra St. 108, Shoubra,PO11629, Cairo, \\ Egypt \\ ${ }^{3}$ Ecole Nationale Supérieure des Mines de Saint-Etienne,158 Cours Fauriel, 42100 Saint-Etienne, \\ France
}

${ }^{4}$ Advanced Forming Research Centre-University of Strathclyde, 85 Inchinnan Dr, Inchinnan, Renfrew PA4 9LJ, United Kingdom

E-mail:mosleh@misis.ru

Keywords: constitutive modeling, titanium alloy, activation energy, superplasticity, processing maps

Abstract

This paper studies the superplasticity of conventional sheets of Ti-1V-4Al-3Mo $(\alpha+\beta)$ alloy. The flow behavior was investigated in a temperature range of $775^{\circ} \mathrm{C}-900{ }^{\circ} \mathrm{C}$ and a constant strain rate range of $2 \times 10^{-4}-5 \times 10^{-3} \mathrm{~s}^{-1}$ via uniaxial tensile tests. The microstructure evolution during the superplastic deformation was analyzed. The results revealed that, the flow behavior of Ti-1V-4Al- 3Mo $(\alpha+\beta)$ alloy is characterized by strain softening phenomena. The experimental stress-strain data were used to build a power law constitutive model. A processing map, which shows the safe and unsafe regions of deformation, was also constructed for the studied alloy. The optimal deformation regime was attained at a temperature of $875{ }^{\circ} \mathrm{C}$ and strain rate of $1 \times 10^{-3} \mathrm{~s}^{-1}$ which provided a $\beta$ phase fraction of $52 \%$. Equiaxed fine-grained $\alpha$ and $\beta$ structure with size of $2-3 \mu \mathrm{m}$ as well as dislocation activity inside the $\alpha$-grains were identified in the optimum deformation regime.

\section{Introduction}

Due to their excellent combination of physical and mechanical properties, titanium alloys are suitable for a wide range of industrial applications. The application fields include military industry, chemical industry, aerospace, biomedical, energy production, marine industry, architecture etc [1,2]. However, one of the main limitations of titanium alloys is their poor formability at room temperature. Superplastic forming (SPF) gives a possibility to produce complex titanium alloy parts under low flow stresses in a single forming operation at elevated temperature. SPF minimizes manufacturing cycle, the amount of joints, component weight and residual stress [1, 3-5]. Mathematical modeling 
facilitates the understanding of the complex behavior of titanium at elevated temperatures. The models estimate the relationships which exist between flow stress, strain rate, strain and temperature. Many studies have focused on the superplastic properties and modeling of superplastic deformation behavior of Ti-6Al-4V alloy [6-15] and only few papers describe these phenomena in Ti-1V-4Al3 Mo alloy $[16,17]$. The differences in the deformation behavior of Ti-6Al-4V and Ti-1V-4Al-3Mo alloys are shown in [16]. Strain hardening is typical for stress-strain behavior of Ti-6Al-4V alloy, while strain softening dominates in Ti-1V-4Al-3Mo alloy. Temperature compared to strain rate, has a stronger influence on the strain hardening and elongation values of this alloy as shown by the Taguchi method [16]. The Arrhenius-type constitutive equation via hyperbolic-sine law successfully predicts the superplastic flow behavior of the alloy with correlation coefficient between the tested and predicted values (R) being 96.3\% [17]. Therefore, more studies are required to successfully understand the superplastic deformation behavior of Ti-1V-4Al-3Mo alloys. Prasad et al [18] proposed processing maps, which are widely utilized for adjusting processing factors and governing microstructure during thermomechanical treatment. Based on dynamic materials model (DMM), in which the workpiece works as a dissipater of power, the processing maps can be constructed [19-23]. In the DD Mmodel, a total power P comprises of two parts:Gand J.Grepresents the power which is transformed totemperature increase. The $\mathrm{J}$ relates to the dissipated power via microstructure evolution, such as recovery, recrystallization and cavitation phenomena [24].

This study aims to investigate the superplasticity of a conventionally processed Ti-1V-4Al-3Mo alloy sheets. The true stress-strain data at constant strain rates were used to develop the constitutive model for predicting the superplastic flow behavior. A processing map was also introduced to identify the safe and un-safe regions of the superplastic deformation. The strain induced microstructure changes were analyzed in order to explain the effect of strain, strain rate and temperature on the superplastic behavior of the studied alloy.

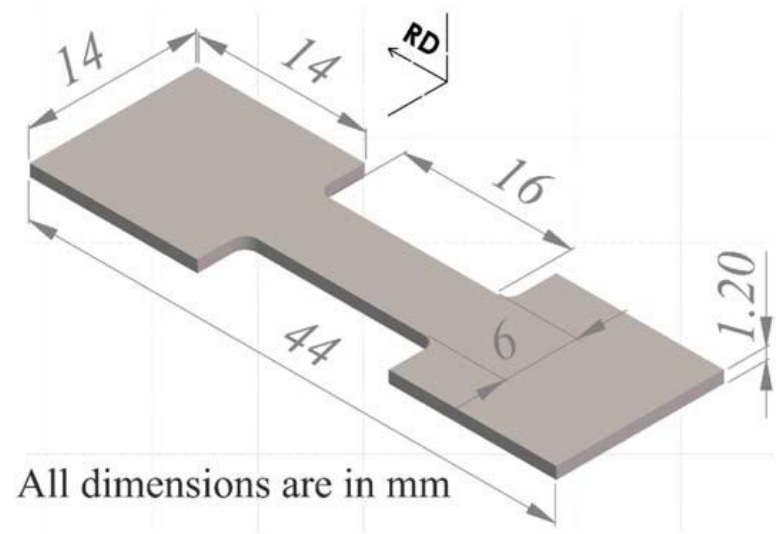

Figure 1. Geometry of the specimen used for the hot uniaxial tensile constant strain rate test 
2. Materials and experimental test

A conventionally processed sheet of Ti-1V-4Al-3Mo alloy was investigated via uniaxial tensile tests at constant strain rate in a temperature-strain rate range of superplasticity using a Walter-BayLFM 100 test machine [25]. Dog-bone type test samples were cut in the sheet rolling direction. The sample size and geometry are shown in figure 1 . The experimental stress-strain data from the uniaxial tensile test at constant strain rate were used to extrapolate the power law Arrhenius type constitutive model for predicting the flow behavior of the studied alloy. The processing map indicating the efficiency of the power dissipation and the unstable deformation regions were constructed via the methods described in $[18,24]$. Microstructure analysis was done for the tested samples after a strain of 1.1 in a strain rate range of $2 \times 10^{-4} \mathrm{~s}^{-1}-1 \times 10^{-3} \mathrm{~s}^{-1}$ and a temperature range of $775{ }^{\circ} \mathrm{C}-875{ }^{\circ} \mathrm{C}$. The samples for microstructure studies were water quenched from the tested temperature immediately after deformation. The samples were mechanically grinded using SiC papers up to $2400 \mathrm{pp}$. The grinded samples were polished using MDChem Cloth with $0.04 \mu \mathrm{m}$ Collodial Silica suspension lubricant. The polished samples were etched in Kroll's reagent and then washed using ethanol in an ultrasonic bath. A Tescan-VEGALMH scanning electron microscope (SEM) was used for the microstructural analysis. For TEM analysis, $3 \mathrm{~mm}$ diameter disc-shaped samples were electrochemically polished and examined via JEOL JEM-2000 EX microscope.

\section{Results and discussions}

\subsection{Constant strain rate tests results}

Figure 2 shows the stress-strain dependences at the studied strain rates and temperatures. The flow behaviour in a strain range of 0.1-1.0 was characterised by strain softening at $775{ }^{\circ} \mathrm{C}-875{ }^{\circ} \mathrm{C}$ (figures 2(a)-(e)). Stable flow with constant stress values was observed at $875^{\circ} \mathrm{C}$ and $2 \times 10^{-4} \mathrm{~s}^{-1}$ (figure 2(e)), as well as $900{ }^{\circ} \mathrm{C}$ and $1 \times 10^{-3} \mathrm{~s}^{-1}$ (figure 2(f)). The peak stress value increased with decreasing temperature and increasing strain rate. The experimental data were utilized for constructing the power law constitutive model. Figure 3 shows the strain hardening coefficient at different strain rates and temperatures. The negative value of strain hardening coefficient (n) means the material is characterized by softening. At $775{ }^{\circ} \mathrm{C}$ and $2 \times 10^{-3} \mathrm{~s}^{-1}$, the $\mathrm{n}$ value was minimum $(-0.6)$ which is indicative of a high strain softening effect. At all tested strain rates, the $\mathrm{n}$ increases with increasing temperature. The strain hardening was close to zero at a temperature of $875{ }^{\circ} \mathrm{C}-900^{\circ} \mathrm{C}$, which is also indicative of the stable flow behavior of the studied alloy. 


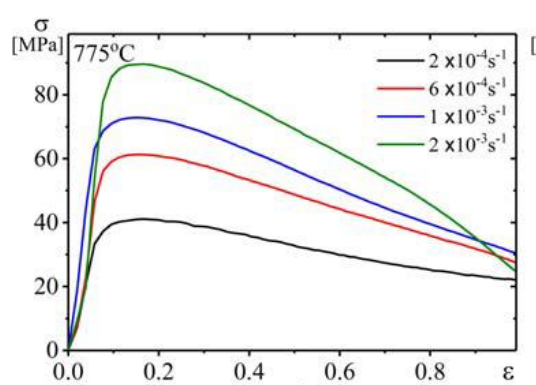

(a)

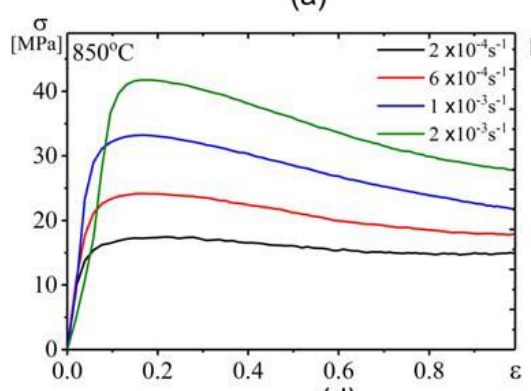

(d)

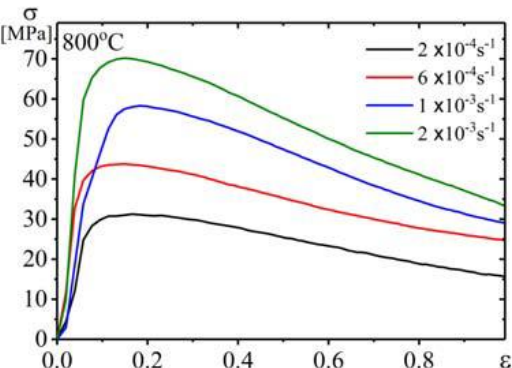

(b)

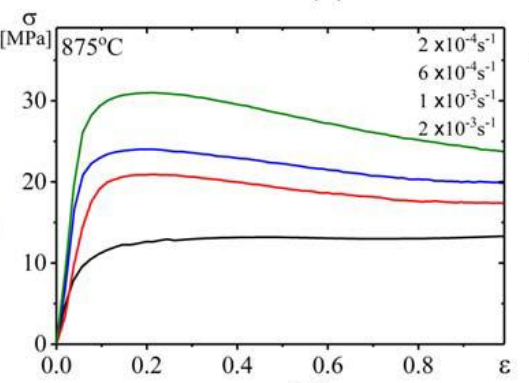

(e)

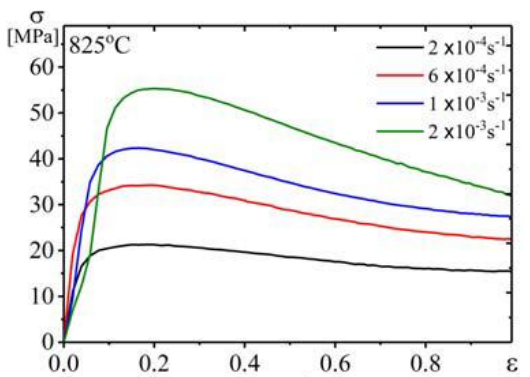

(c)

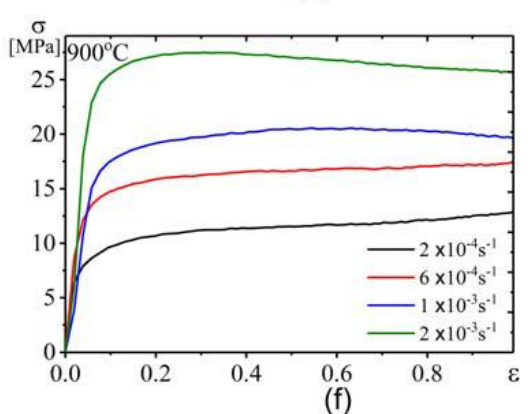

Figure 2. Stress-strain rate at different strain rates and temperatures (a) $775^{\circ} \mathrm{C}$, (b) $800{ }^{\circ} \mathrm{C}$, (c) $825^{\circ} \mathrm{C}$, (d) $850^{\circ} \mathrm{C}$, (e) $875^{\circ} \mathrm{C}$, and (f) $900^{\circ} \mathrm{C}$

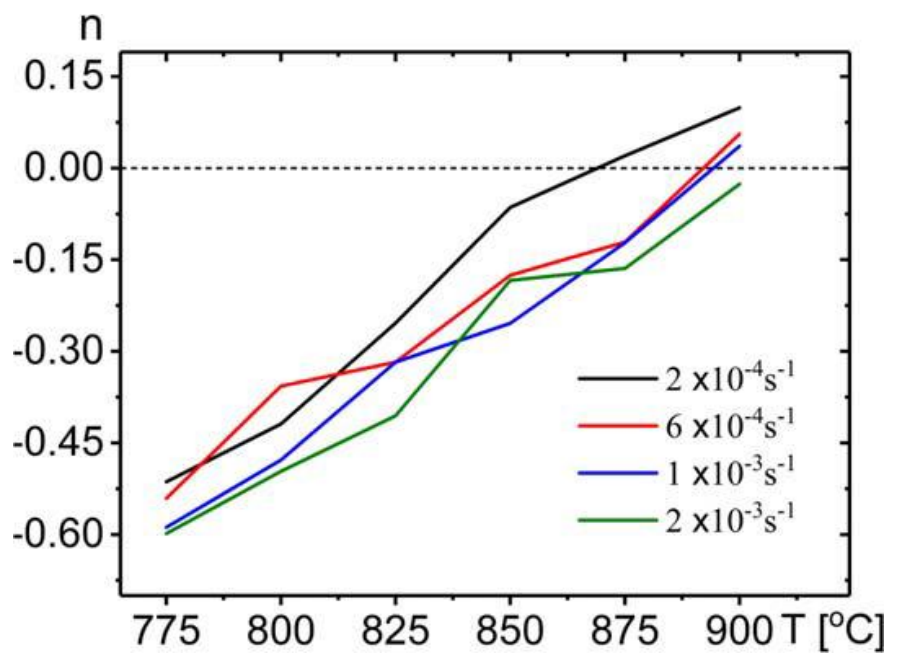

Figure 3. Strain hardening coefficient (n) dependence versus temperature at different strain rates

\subsection{Modeling experiments}

At elevated temperature, Zener-Holloman parameter $(Z)$ and exponent equation describe the relation between the flow stress, deformation temperature and strain rate as shown in equations (1), (2) [26, 27]. The power law was used to construct a simple model for predicting the flow behavior of the studied alloy. The power law has also been used in some works to describe the low stress values at superplastic temperatures [28]. 


$$
\begin{aligned}
& z=\dot{\varepsilon}=\exp \left(\frac{Q}{R T}\right) \\
& \dot{\varepsilon}=A \times \sigma^{n_{1}} \times \exp \left(-\frac{Q}{R T}\right)
\end{aligned}
$$

where, $\dot{\varepsilon}, \sigma, \mathrm{T}$, are the strain rate in $\mathrm{s}^{-1}$, the flow stress in $\mathrm{MPa}$ and the temperature in $\mathrm{K}$, respectively. $A$ and $n_{1}$ are the material constants. $Q$ is an effective (apparent) activation energy of deformation in $\mathrm{KJ}$ $\mathrm{mol}-1, \mathrm{R}=8.314 \mathrm{~J} /(\mathrm{mol} \mathrm{K})$ is a universal gas constant.

\subsubsection{Power law model constants determination}

The obtained experimental stress-strain data (figure 1) are deployed for determining the power law model constants. The detailed procedures of computing these constants at a strain of 0.4 , are explained as follows:

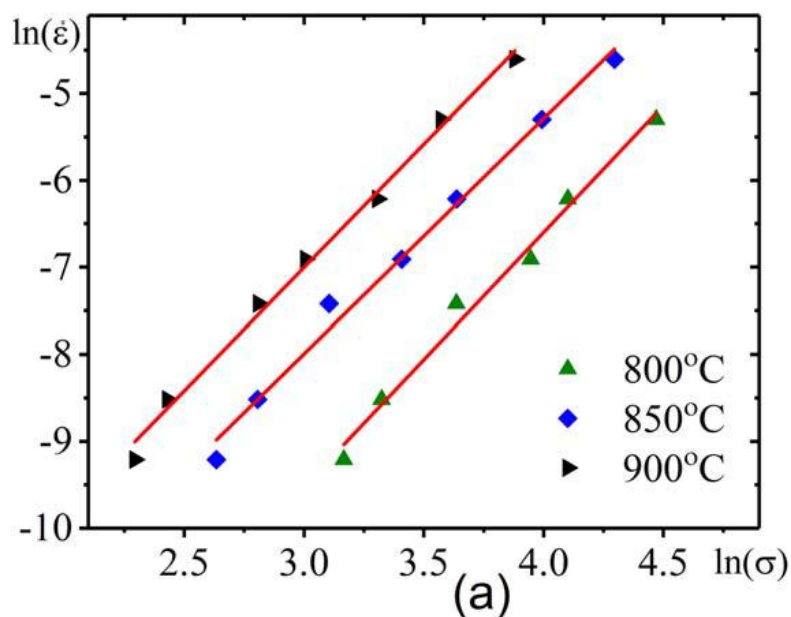

(a)

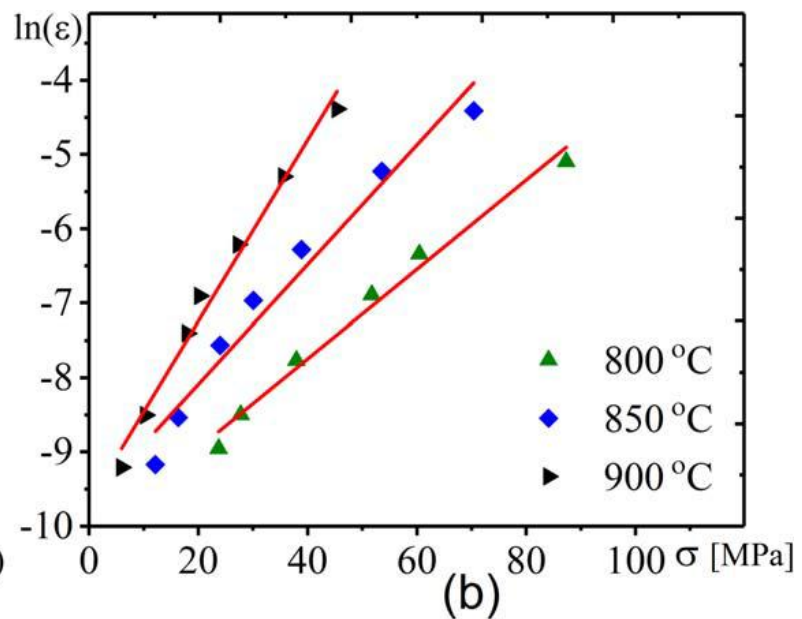

(b)

Figure 4. The plots of (a) $\ln \dot{\varepsilon}-\ln \sigma$; (b) $\ln \dot{\varepsilon}-\sigma$.

Table 1. The computed values of the constants of power law model

\begin{tabular}{lrrrrrrl}
\hline Parameter & \multicolumn{1}{c}{$Y_{1}$} & \multicolumn{1}{c}{$B_{1}$} & \multicolumn{1}{c}{$B_{2}$} & \multicolumn{1}{c}{$B_{3}$} & \multicolumn{1}{c}{$B_{4}$} & \multicolumn{1}{c}{$B_{5}$} & $R$ \\
\hline$Q$ & 296.10 & -129.15 & 676.20 & -2583.45 & 3461.41 & -1637.78 & 99.99 \\
$n_{1}$ & 4.10 & -30.26 & 243.04 & -972.04 & 2160.61 & -2703.51 & 99.5 \\
$\operatorname{Ln}(A)$ & 12.76 & 31.33 & -175.67 & 304.29 & -240.44 & 59.86 & 99.96 \\
\hline
\end{tabular}

Taking the natural logarithm of both sides of (equations (2), (3)) can be obtained

$$
\ln \dot{\varepsilon}=\ln (A)+n_{1} \ln \sigma-\frac{Q}{R T} ; n_{1}=\left[\frac{\partial \ln \dot{\varepsilon}}{\partial \ln \sigma}\right]_{T}
$$

The $\mathrm{Q}$ (equation (4)) can be obtained by taking the partial differentiation of equation (3) 


$$
Q=R \times\left[\frac{\partial \ln \dot{\varepsilon}}{\partial \ln \sigma}\right]_{T} \times\left[\frac{\partial \ln \sigma}{\partial\left(\frac{1}{T}\right)}\right]_{\dot{\varepsilon}}
$$

Figure 4 shows the linear plots of $\ln \dot{\varepsilon}$ - $\ln \sigma$ (figure 4(a)), $\ln \dot{\varepsilon}-\sigma$ (figure 4(b)). The values of $n_{1}, \ln (A)$ and $\mathrm{Q}$ were computed as the average values of the slopes of the $\ln \dot{\varepsilon}-\ln \sigma$ and $\ln \dot{\varepsilon}-\sigma$ plots, respectively (figures 4(a), (b)). According to the power law function, the values of the strain rate and flow stress can be expressed as following (equations (5) and (6)).

$$
\begin{gathered}
\dot{\varepsilon}=6.4 \times 10^{4}\left[\sigma^{2.815} \times \exp \left(-\frac{257.7 \times 1000}{R T}\right)\right] \\
\sigma=\left(\frac{Z}{A}\right)^{\frac{1}{n_{1}}}=\left(\frac{\dot{\varepsilon} \times \exp \left(\frac{257.7 \times 1000}{R T}\right)}{6.4 \times 10^{4}}\right)^{\frac{1}{2.815}}
\end{gathered}
$$

\subsubsection{The dependence of material constants on strain}

At a strain range from 0.1 to 1.0 , the material constants $\mathrm{n} 1, \mathrm{Q}$ and $\mathrm{A}$ were computed to address the effect of strain on the material constants values. The procedure to determine the solution of these constants is like that at strain of 0.4. Figure 4 shows the dependence of material constants versus strain $\varepsilon$. The influence of strain on the material constants was regressed by 5 th order polynomial fitting method, which provided minimum error levels. The material constants were significantly affected by the strain at all tested conditions. The fitted equations were expressed by equation (7). The regressing coefficients of each equation are listed in table 1.

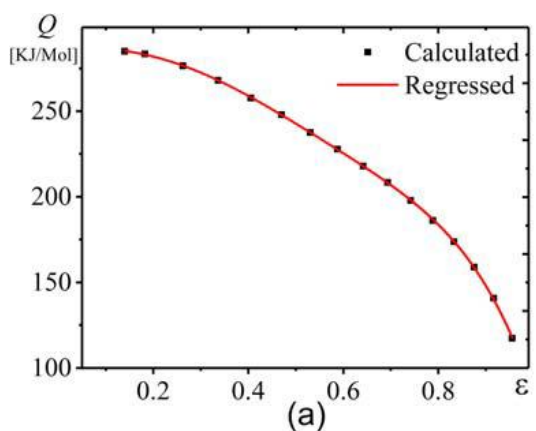

(a)

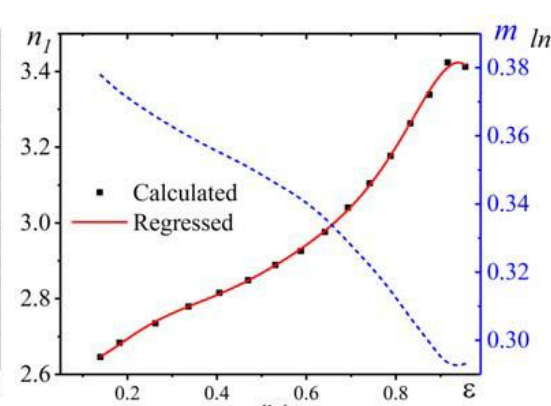

(b)

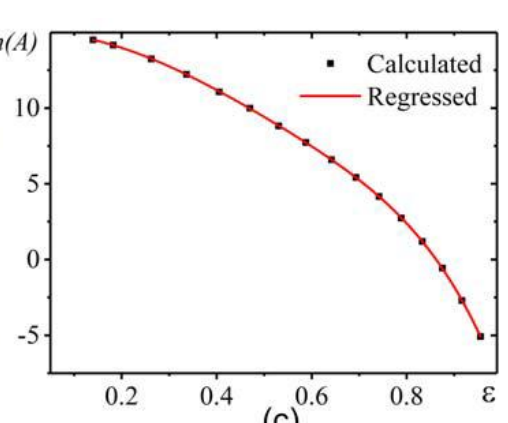

(c)

Figure 5. Variation of (a) Q, (b) $\mathrm{n} 1(\mathrm{~m})$, and (c) $\ln (\mathrm{A})$ constants versus true strain ( $($ )

$$
\left\{\begin{array}{l}
Q_{1}=Y_{1}+B_{1} \varepsilon^{1}+B_{2} \varepsilon^{2}+B_{3} \varepsilon^{3}+B_{4} \varepsilon^{4}+B_{5} \varepsilon^{5} \\
n_{1}=Y_{1}+B_{1} \varepsilon^{1}+B_{2} \varepsilon^{2}+B_{3} \varepsilon^{3}+B_{4} \varepsilon^{4}+B_{5} \varepsilon^{5} \\
A=Y_{1}+B_{1} \varepsilon^{1}+B_{2} \varepsilon^{2}+B_{3} \varepsilon^{3}+B_{4} \varepsilon^{4}+B_{5} \varepsilon^{5}
\end{array}\right.
$$

The $\mathrm{Q}$ and $\mathrm{n}_{1}$ parameters are related to the deformation mechanisms and microstructure evolution. The effective activation energy Q slightly decreased from 285 to $180 \mathrm{~kJ} \mathrm{~mol}^{-1}$ with increasing strain up to 0.8 then dramatically decreased to $55 \mathrm{~kJ} \mathrm{~mol}^{-1}$ up to strain of 1.0 (figure $5(\mathrm{a})$ ). The $\mathrm{Q}$ values for 
Ti-6Al-4V, Ti-Al-Mn and Ti-6Al-2Sn-4Zr-2Mo are within the ranges of 300- $330 \mathrm{~kJ} \mathrm{~mol}^{-1}$ [29-31], $285-180 \mathrm{~kJ} \mathrm{~mol}^{-1}$ [12] and 298-442 $\mathrm{kJ} \mathrm{mol}^{-1}$ [32] respectively. Q values of 250-300 kJ mol${ }^{-1}$ at low strains were obtained in the studied alloy. These Q values are associated with thermally activated dislocation motion. The $\mathrm{Q}$ value decreasing with increasing strain, may be related to the effect of dynamic recrystallization [31]. Dynamic recrystallization led to the formation of more equiaxed grain structure and increased grain boundaries thereby simplifying the grain boundaries diffusion and grain boundary sliding. The behavior of $Q$ and constant $\ln (\mathrm{A})$ versus strain was similar (figure 5(c)).

The $\mathrm{n}_{1}$-value increased and $\mathrm{m}$-value decreased with increasing strain to 0.8 then decreased again up to 1 (figure $5(\mathrm{~b})$ ). The strain rate sensitivity index $m$ relates the $n_{1}$ value as $m=1 / n_{1}$, thus $m$-value is inversely proportional to $n_{1}$. Them-value was varied in a range of $0.3-0.4$ and these values may be attributed to superplastic behavior with deformation mechanisms of grain boundaries sliding and dislocation motion. The lower m-values at the beginning of the deformation could be attributed to the partially recrystallized grain structure and decreased grain boundary sliding. However, increasing mvalue at strains more than 0.9 could be as a consequence of complete recrystallization and a corresponding increase in grain boundary sliding.

\subsubsection{Model validation}

For verifying the precision of the constructed power law constitutive model, a comparison between the modeled flow behavior and the obtained experimental flow behavior was done. The accuracy of the constructed power law constitutive model is appraised via the following terms (equations (8)(10)):

$$
\begin{gathered}
\text { Correlation coefficient }(R)=\frac{\sum_{i=1}^{N}\left(E_{i}-\bar{E}\right)\left(P_{i}-\bar{P}\right)}{\sqrt{\sum_{i=1}^{N}\left(E_{i}-\bar{E}\right)^{2}} \sum_{i=1}^{N}\left(P_{i}-\bar{P}\right)^{2}} \\
\text { Average absolute relative error }(A A R E)=\frac{1}{N} \sum_{i=1}^{N}\left|\frac{E_{i}-P_{i}}{E_{i}}\right| \\
\text { Root mean square error }(R M S E)=\sqrt{\frac{1}{N} \sum_{i=1}^{N}\left(E_{i}-P_{i}\right)^{2}}
\end{gathered}
$$

where $E_{i}, P_{i}, \bar{E}, \bar{P}$ and $\mathrm{N}$ are the experimental data, the modeled flow data, the average value of the experimental data, the average value of the modeled flow stress and the total number of the data used, respectively. Figure 6 shows the experimental and predicted flow behavior after power law constitutive modeling. The correlation between the experimental and predicted flow behavior is 
shown in figure 6 . The predicted flow stresses have an excellent agreement with the experimental stresses. The values of R, AARE and RMSE are 97.4\%, 6.4\% and 3.1, respectively. Therefore, the flow behavior of Ti-1V-4Al-3Mo alloy can be successfully predicted using the power law constitutive model.

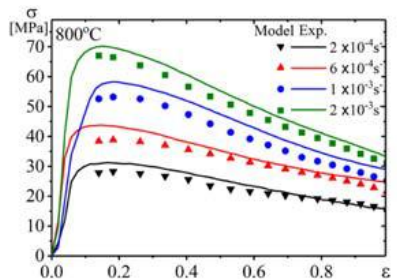

(a)

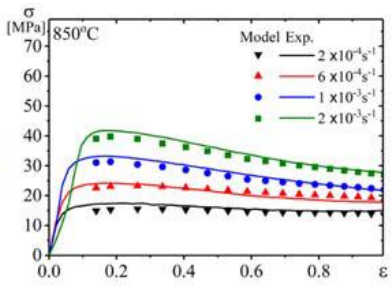

(b)

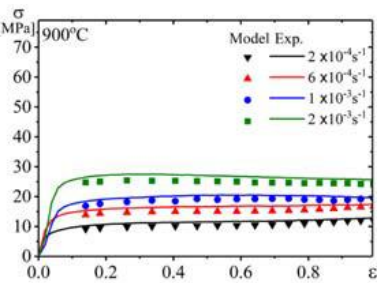

(c)

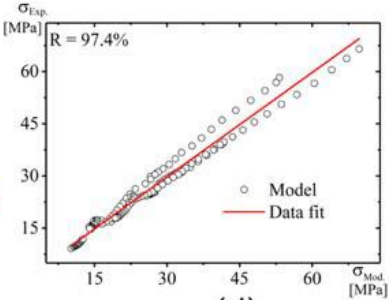

(d)

Figure 6. Comparative plots for the experimental results (lines) and predicted values by simple law model (symbols) at (a) $800{ }^{\circ} \mathrm{C}$, (b) $850{ }^{\circ} \mathrm{C}$, (c) $900{ }^{\circ} \mathrm{Cand}$ (d) the correlation between experimental and fitted flow stress.
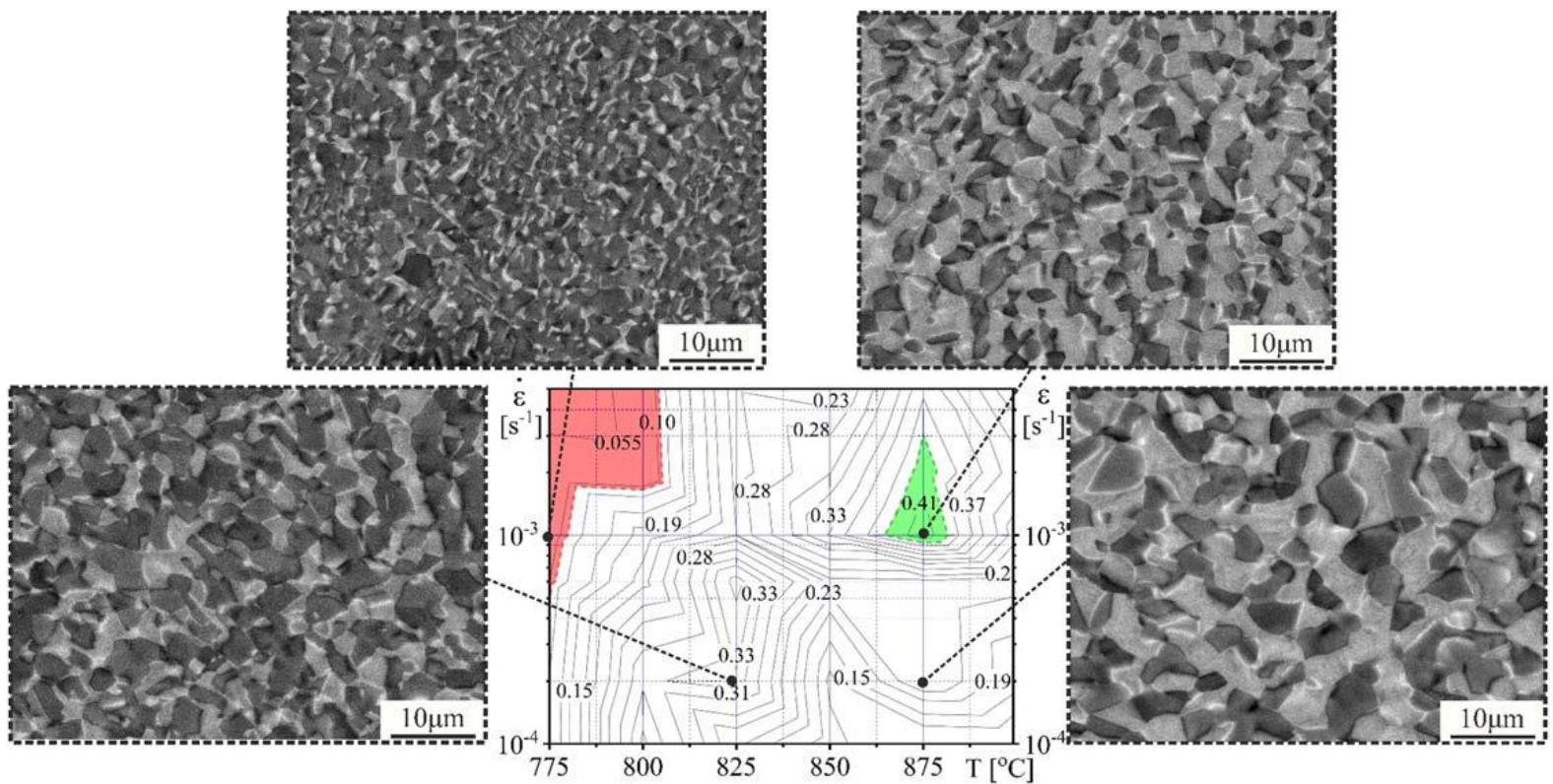

Figure 7. Efficiency contours of power dissipation of the deformation of Ti-1V-4Al-3Mo alloy at the strains of 1.1

\section{Processing map analysis}

It is known that, materials exposed to hot deformation dissipate the applied power non-linearly [33]. Strain rate sensitivity index $(\mathrm{m})$ is the factor that partitions the applied power between heat and microstructure evolution. The power dissipation efficiency $\eta$ and the instability parameter $\xi_{\dot{\varepsilon}}$, which are related to the work of hot deformation, can be expressed by the strain rate sensitivity $\mathrm{m}$ as follows (equations (11) and (13)) [34-40]: 


$$
\begin{aligned}
& \eta=\frac{2 m}{m+1} \\
& m=\left(\frac{\partial \ln (\sigma)}{\partial \ln (\dot{\varepsilon})}\right)_{T, \dot{\varepsilon}} \\
& \xi_{(\dot{\varepsilon})}=\frac{\partial\left(\frac{m}{m+1}\right)}{\partial \ln (\dot{\varepsilon})}+m<0
\end{aligned}
$$

where both $\eta$ and $\xi$ values with different temperatures and strain rates can be represented as a threedimensional graph called 'processing map'. In general, processing maps help us to easily recognize the proper temperature strain rate hot working range, in which microstructurally 'safe' mechanisms, like a dynamic recrystallization, occur and avoid an unstable flow [19, 34, 41]. According to [14] and [36], higher values of $\eta$ are representative of the best hot deformation conditions. Figure 7 shows the processing map and microstructure evolution at strain of 1.1. In the studied temperature-strain rate range, the green areas indicate the high $\eta$ regions, which might be good for superplastic deformation and the red area indicate unstable deformation region figure 7 . The microstructure plays an important role on both the flow behavior and the stability of the deformation process. A fine and equiaxed grained structure provides necking free flow and large elongation [42]. The temperature providing 20 to $50 \% \beta$-phase is optimal for a superplastic deformation [42]. The microstructures after 1.1 strain at various testing regimes are shown in figure 7 and the microstructure parameters are shown in table 2 .

Table 2. The microstructure parameters at various testing regimes and strain of 1.1

\begin{tabular}{lcccc}
\hline Condition & $\mathrm{d}_{\alpha}(\mu \mathrm{m})$ & $\mathrm{d}_{\beta}(\mu \mathrm{m})$ & $\mathrm{V}_{\alpha}(\%)$ & $\mathrm{V}_{\beta}(\%)$ \\
\hline $775^{\circ} \mathrm{C} / 1 \times 10^{-3} \mathrm{~s}^{-1}$ & $1.8 \pm 0.2$ & $1.0 \pm 0.2$ & $66 \pm 4$ & $33 \pm 3$ \\
$825^{\circ} \mathrm{C} / 2 \times 10^{-4} \mathrm{~s}^{-1}$ & $2.2 \pm 0.3$ & $2.2 \pm 0.2$ & $55 \pm 4$ & $44 \pm 4$ \\
$875^{\circ} \mathrm{C} / 2 \times 10^{-4} \mathrm{~s}^{-1}$ & $3.0 \pm 0.3$ & $3.4 \pm 0.3$ & $45 \pm 4$ & $54 \pm 5$ \\
$875^{\circ} \mathrm{C} / 1 \times 10^{-3} \mathrm{~s}^{-1}$ & $2.3 \pm 0.3$ & $2.6 \pm 0.3$ & $48 \pm 3$ & $52 \pm 4$ \\
\hline
\end{tabular}

The maximum efficiency $\eta$ of 0.41 was attained at the strain rate of $1 \times 10^{-3} \mathrm{~s}^{-1}$ and temperature of 875 ${ }^{\circ} \mathrm{C}$. This $\eta$-value is close to the typical efficiency value associated with dynamic recrystallization [20, 25 , 43]. At this deformation regime, the $\beta$ phase fraction was $52 \pm 4 \%$, and the microstructure was equiaxed and homogeneous due to successful continuous dynamic recrystallization at the initial stage of superplastic deformation [25, 43]. A similar grain structure with fine grains of both phases and $\beta$ fraction of $44 \%$ was observed at low strain rates of $(2-6) \times 10^{-4} \mathrm{~s}^{-1}$ and at lower temperature of $825^{\circ} \mathrm{C}$. This regime also provided an increased efficiency and a good superplasticity. Fine, equiaxed and stable grain structure with increased temperature simplify the grain boundary sliding and its accommodation by dislocation and diffusion creep which are the superplastic deformation 
mechanisms [5, 44-46]. Low strain rate of $2 \times 10^{-4} \mathrm{~s}^{-1}$ at $87^{\circ} \mathrm{C}$ led to significant dynamic grain growth, thereby resulting in an unstable flow and a low efficiency value. The main possible reason of dynamic grain growth is the migration of grain boundaries during the superplastic deformation that intensified with increasing temperature [47-49]. The efficiency value related to dynamic grain growth was below 0.2. Current results showed lower efficiency for the dynamic grain growth in the studied deformation regimes as compared to the typical values attained for hot deformation processes; $\eta=0.3-0.4[20,50]$. This trend may be attributed to the high sensitivity of superplastic flow to grain size; an important parameter when considering stability in superplastic flow [31, 36, 42, 43]. The strain of 1.1 at $775^{\circ} \mathrm{C}$ with strain rate of $1 \times 10^{-3} \mathrm{~s}^{-1}$ led to a non-equiaxed inhomogeneous grain structure due to limited dynamic recrystallization and low diffusivity at low deformation temperature. This may be as a result of the unstable deformation and a low efficiency (red zone in map). Figure 8 shows the TEM analysis of Ti-1V-4Al-3Mo alloy after strain of 1.1 and at low temperature of $775^{\circ} \mathrm{C}$ and optimal temperature of $875^{\circ} \mathrm{C}$ and at strain rate of $1 \times 10^{-3} \mathrm{~s}^{-1}$. Because of martensitic transformation at rapid cooling of the $\beta$ phase, the dislocation structure of the $\beta$ phase was changed by both the deformation process and the martensitic transformation. Thus, it was difficult to evaluate the deformation related structural changes. The dislocation structure of the $\alpha$-phase confirmed the high dislocation activity at $775^{\circ} \mathrm{C}$. The dislocations activity and dislocation walls were also observed at the optimal temperature of 875 ${ }^{\circ} \mathrm{C}$, but the number of dislocations was significantly lower.

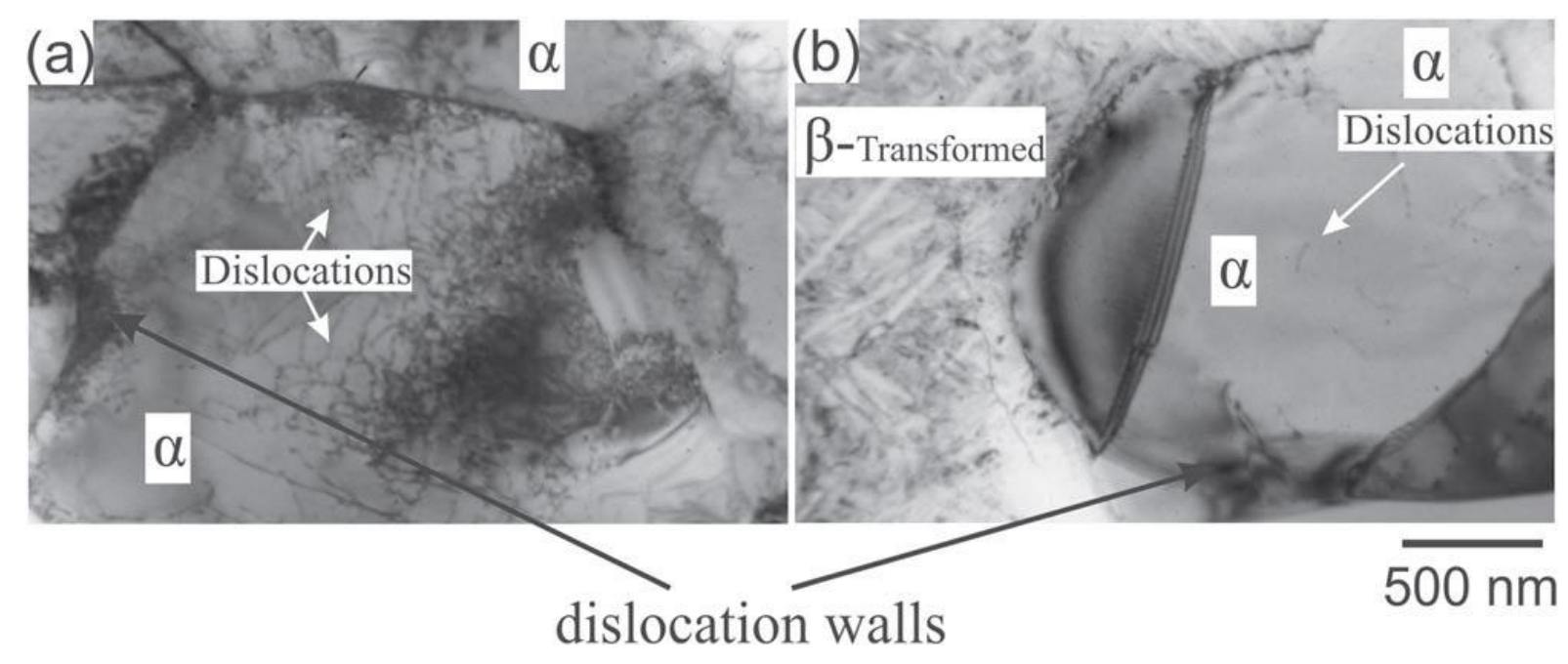

Figure 8.TEM structure of the Ti-1V-4Al-3Mo alloy after 1.1 strain at $1 \times 10^{-3} \mathrm{~s}^{-1}$ with strains of 1.1 at (a) $775^{\circ} \mathrm{C}$ and (b) $875^{\circ} \mathrm{C}$

\section{Conclusions}

The superplastic flow behavior of Ti-1V-4Al-3Mo alloy was investigated. A power law constitutive model was developed for predicting the flow behavior of the studied alloy. A processing map was 
constructed to indicate the safe and unsafe deformation regions of the studied alloy. Based on the results, we concluded that:

1. The flow behavior of Ti-1V-4Al-3Mo alloy was predominantly characterized by strain softening and the strain hardening coefficient (n) was increased from -0.6 to 0.1 with increasing testing temperature and decreasing strain rate. The maximum elongation was attained at $\mathrm{n}$ value close to zero.

2. The predicted flow behavior was in excellent agreement with the obtained experimental flow behavior of Ti-1V-4Al-3Mo alloy. The values of R, AARE and RMSE are 97.4\%, 6.4\% and 3.1, respectively. Therefore, the flow behavior of Ti-1V-4Al-3Mo alloy can successfully predicted using power law.

3. The processing map exhibits unsafe region with low efficiency at $775^{\circ} \mathrm{C}-800^{\circ} \mathrm{C}$ and $\geq 1 \times 10^{-3} \mathrm{~s}^{-1}$ as a result of non-uniform and non-equiaxed grain structure of the alloy at these conditions. High efficiency and stable superplastic flow were observed at $825{ }^{\circ} \mathrm{C} /(2-6) \times 10^{-4} \mathrm{~s}^{-1}$ and $875^{\circ} \mathrm{C} /(0.8-3)$ $10^{-3} \mathrm{~s}^{-1}$ with the maximum efficiency at $875^{\circ} \mathrm{C}$ and $1 \times 10^{-3} \mathrm{~s}^{-1}$. The grain structure at aforementioned beneficial regimes was equiaxed, homogeneous and fine with $\beta$ phase fraction of $44 \%-52 \%$.

Acknowledgments

The mechanical tests, microstructure evolution and modeling experiments were supported by RSF Grant\#18- 79-00348. The authors also gratefully acknowledge the financial support of the Ministry of Science and Higher Education of the Russian Federation in the framework of Increase Competitiveness Program of MISiS (Support project for young research engineers) for supporting the processing map analysis. We also wish to dedicate this work to the memory of Prof. V.K Portnoy. We are extremely thankful for his guidance, patience and support. He was always nice, calm, and he taught us how to be always optimistic, even in the dark.

\section{References}

[1] Leyens C and Peters M, 2002, Titanium an Titanium Alloys (England: Wiley) (https://doi.org/10.1002/3527602119)

[2] Moiseyev V.N, 2005, Titanium Alloys Russian Aircraft and Aerospace Applications (Boca Raton, FL: CRC Press) (CRC Press) (https://doi.org/10.1017/CBO9781107415324.004)

[3] Boyer R. R, 1995, Titanium for aerospace: rationale and applications Adv. Perform. Mater. 2 34968

[4] Moiseyev V.N, 2006, Titanium alloys: Russian aircraft and aerospace applications

[5] Nieh T.G, Wadsworth J and Sherby O.D, 2014, Superplasticity in Metals and Ceramics (Cambridge: Cambridge University Press) (https://doi.org/10.1007/s13398-014-0173-7.2) 
[6] Tabei A, Abed F.H, Voyiadjis G.Z and Garmestani H, 2017, Constitutive modeling of Ti-6Al-4V at a wide range of temperatures and strain rates Eur. J. Mech. A/Solids, 63, 128-35

[7] Sirvin Q, Velay V, Bonnaire R and Penazzi L, 2019, Mechanical behaviour modelling and finite element simulation of simple part of Ti-6Al-4V sheet under hot/warm stamping conditions J. Manuf. Process., 38, 472-82

[8] Guo L, Li B and Zhang Z, 2013, Constitutive relationship model of TC21 alloy based on artificial neural network Trans. Nonferrous Met.Soc. China, 23, 1761-5

[9] Zhao J, Ding H, Zhao W, Huang M, Wei D and Jiang Z ,2014, Modelling of the hot deformation behaviour of a titanium alloy using constitutive equations and artificial neural network Comput. Mater. Sci.,92, 47-56

[10] Porntadawit J, Uthaisangsuk V and Choungthong P, 2014, Modeling of flow behavior of Ti-6Al$4 \mathrm{~V}$ alloy at elevated temperatures Mater.Sci. Eng. A, 599, 212-22

[11] Hajari A, Morakabati M, Abbasi S.M and Badri H, 2017, Constitutive modeling for hightemperature flow behavior of Ti-6242S alloy Mater. Sci. Eng. A, 681, 103-13

[12] Mosleh A, Mikhaylovskaya A, Kotov A, Pourcelot T, Aksenov S, Kwame J and Portnoy V, 2017, Modelling of the superplasticdeformation of the near-atitanium alloy (Ti-2.5Al-1.8Mn) using arrhenius-type constitutive model and artificial neural network Metals (Basel), 7, 568

[13] Velay V, Matsumoto H, Vidal Vand Chiba A, 2016, Behavior modeling and microstructural evolutions of Ti-6Al-4V alloy under hot forming conditions Int. J. Mech. Sci., 108-109, 1-13

[14] Li L and Li M, 2017, Constitutive model and optimal processing parameters of TC17 alloy with a transformed microstructure via kinetic analysis and processing maps Mater. Sci. Eng. A, 698, 302-12

[15] Mosleh A.O, Mikhaylovskaya A.V, Kotov A.D, Kwame J.S and Aksenov S.A, 2019, Superplasticity of Ti-6Al-4V titanium alloy: microstructure evolution and constitutive modelling Materials (Basel), 12, 1756-8 Mater. Res. Express 6 (2019) 096584 AOMosleh et al

[16] Mosleh AO, Mikhaylovskaya A, Kotov AD, AbuShanab W, Moustafa E and Portnoy V, 2018, Experimental investigation of the effect of temperature and strain rate on the superplastic deformation behavior of Ti-based alloys in the $(\alpha+\beta)$ temperature field Metals (Basel), 8, 819

[17] Mosleh A.O, Mikhaylovskaya A.V, Kotov A.D and Portnoy V.K, 2018, Arrhenius-type constitutive equation model of superplastic deformation behaviour of different titanium based alloys Defect Diffus. Forum, 385, 45-52

[18] Prasad Y.V.R.K and Seshacharyulu T, 2014, Modelling of hot deformation for microstructural control Int. Mater. Rev., 43, 243-58

[19] Hu M, Dong L, Zhang Z, Lei X, Yang R and Sha Y, 2018, A novel computational method of processing map for Ti-6Al-4V alloy and corresponding microstructure study Materials (Basel), 11, 1599

[20] Long S, Xia Y.F, Wang P, Zhou Y.T, Gong-Ye F.J, Zhou J, Zhang J.S and Cui M.L, 2019, Constitutive modelling, dynamic globularization behavior and processing map for Ti-6Cr-5Mo-5V4Al alloy during hot deformation J. Alloys Compd., 796, 65-76 
[21] Xia Y, Long S, Zhou Y, Zhao J, Wang T and Zhou J, 2016, Identification for the optimal working parameters of Ti-6Al-4V-0.1Ru alloy in a wide deformation condition range by processing maps based onDMMMater. Res., 19, 1449-60

[22] Wan P, Wang K, Zou H, Lu S and Li X, 2019, Study on hot deformation and process parameters optimization of Ti-10.2Mo-4.9Zr-5.5Sn alloy J. Alloys Compd., 777, 812-20

[23] Rajput S. K, Dikovits M, Chaudhari G.P, Poletti C, Warchomicka F, PancholiVand Nath S K, 2013, Physical simulation of hot deformation and microstructural evolution of AISI 1016 steel using processing maps Mater. Sci. Eng. A, 587, 291-300

[24] Luo J, Li M, YuW and Li H, 2009, Effect of the strain on processing maps of titanium alloys in isothermal compression Mater. Sci. Eng. A, 504, 90-8

[25] KotovA.D, Mikhailovskaya A.V, Mosleh A.O and Pourcelot T. P, 2019, Superplasticity of an ultrafine-grained Ti-4\%Al-1\%V-3\%Mo titanium alloy Phys. Met. Metallogr., 120, 66-74

[26] Sellars C.M and McTegart W.J, 1966, On the mechanism of hot deformation Acta Metall., 14, $1136-8$

[27] Zener C and Hollomon J.H, 1944, Effect of strain rate upon plastic flow of steel J. Appl. Phys. $15,22-32$

[28] Qi L, Hao Q, ZhaoHand Zhang Y, 2018, Constitutive equation and processing map of CuNi10Fe1Mn alloy based on high-temperature deformation behavior Mater. Res. Express, 5, 056526

[29] Mishra R. S, Stolyarov V.V, Echer C, Valiev R. Z and Mukherjee A.K, 2001, Mechanical behavior and superplasticity of a severe plastic deformation processed nanocrystalline $\mathrm{Ti}-6 \mathrm{Al}-4 \mathrm{~V}$ alloy Mater. Sci. Eng. A, 298, 44-50

[30] Seshacharyulu T, Medeiros S.C, FrazierW.G and Prasad Y.V.R.K, 2000, Hot working of commercial $\mathrm{Ti}-6 \mathrm{Al}-4 \mathrm{~V}$ with an equiaxed $\alpha-\beta$ microstructure: materials modeling considerations Mater. Sci. Eng. A, 284, 184-94

[31] Matsumoto H and Velay V, 2017, Mesoscale modeling of dynamic recrystallization behavior, grain size evolution, dislocation density, processing map characteristic, and room temperature strength of Ti-6Al-4V alloy forged in the $(\alpha+\beta)$ region J. Alloys Compd., 708, 404-13

[32] Hayes R.W, Viswanathan G.B and Mills M.J, 2002, Creep behavior of Ti-6Al-2Sn-4Zr-2Mo: I. The effect of nickel on creep deformation and microstructure Acta Mater., 50, 4953-63

[33] Prasad Y.V.R.K, Rao K.P and Sasidhara S, 2015, Hot Working GuideASMInt. 636

[34] Prasad Y.V.R.K, 2013, Processing maps: a status report J. Mater. Eng. Perform. 22, 2867-74

[35] Sun C, Zuo X, Xiang Y and Yang J, 2016, Investigation on hot deformation behavior and hot processing map of BSTMUF601 super-alloy Metals (Basel), 6, 70

[36] Luo J, Ye P, LiM Q and Liu L.Y, 2015, Effect of the alpha grain size on the deformation behavior during isothermal compression of Ti-6Al-4V alloy Mater. Des., 88, 32-40

[37] Li Y. L, Wang W.X, Zhou J and Chen H.S, 2017, Hot deformation behaviors and processing maps of B4C/A16061 neutron absorber composites Mater. Charact., 124, 107-16 
[38] Kil T.D, Lee J.M and Moon Y.H, 2014, Formability estimation of ring rolling process by using deformation processing map Procedia Eng.,81, 298-303

[39] Duan Y, Ma L, Qi H, Li R and Li P, 2017, Developed constitutive models, processing maps and microstructural evolution of Pb-Mg-10Al-0.5B alloy Mater. Charact., 129, 353-66

[40] Sanrutsadakorn A, Uthaisangsuk V, Suranuntchai S and Thossatheppitak B, 2013, Investigation of hot deformation characteristics of AISI 4340 steel using processing map Adv. Mater. Res 683 3016

[41] Roy S and Suwas S, 2013, The influence of temperature and strain rate on the deformation response and microstructural evolution during hot compression of a titanium alloy $\mathrm{Ti}-6 \mathrm{Al}-4 \mathrm{~V}-0.1 \mathrm{~B}$ J. Alloys Compd., 548, 110-25

[42] Sieniawski J and Motyka M, 2007, Superplasticity in titanium alloys J. Achiev. Mater. Manuf. Eng., 24, 123-30

[43] Imai H, Yamane G, Matsumoto H, Vidal Vand Velay V, 2019, Superplasticity of metastable ultrafine-grained Ti 6242S alloy: mechanical flow behavior and microstructural evolution Mater. Sci. Eng. A, 754, 569-80

[44] Alabort E, Kontis P, Barba D, Dragnevski K and Reed R.C, 2016, On the mechanisms of superplasticity in Ti-6Al-4V Acta Mater., 105, 449-63

[45] Zhou G, Chen L, Liu L, Liu H, Peng H and Zhong Y, 2018, Low-temperature superplasticity and deformation mechanism of Ti-6Al-4V alloy Materials (Basel), 11, 1212

[46] Kawasaki M and Langdon T.G, 2018, Superplasticity in ultrafine-grained materials Rev. Adv. Mater. Sci, 54, 46-55

[47] Rabinovich M.K and Trifonov V.G, 1996, Dynamic grain growth during superplastic deformation Acta Mater., 44, 2073-8

[48] Zelin M and Industries I.A, 2002, Grain growth during superplastic deformation Interface Sci., $7475,37-42$

[49] Tan M.J, 2007, Cavitation and grain growth during superplastic forming Manuf. Eng., 24, 30714

[50] Balasundar I, Raghu T and Kashyap B. P, 2013, Modeling the hot working behavior of near- $\alpha$ titanium alloy IMI 834 Prog. Nat. Sci. Mater. Int., 23, 598-607 